\title{
El legado de Jorge Peña Hen: las orquestas sinfónicas infantiles y juveniles en Chile y en América Latina
}

\author{
por \\ Olivia Concha Molinari \\ Universidad de La Serena, Chile \\ conchamolinari@gmail.com
}

Con gran satisfacción moral y espiritual celebramos la iniciativa de la Orquesta Juvenil de las Américas (Youth Orchestra's America, YOA) con sus 80 integrantes de 20 países, entre los cuales figuran 15 jóvenes chilenos, de fijar a Chile -según su propia declaración pública- "como sede de su gira de conciertos 2012 con el propósito de conmemorar el papel de Chile en el origen del movimiento social de Orquestas Juveniles en las Américas y el legado del Maestro Jorge Peña Hen”.

Es significativa la dinámica de la denominada "residencia" de la gran orquesta YOA. Consiste en la estadía por 15 días en una ciudad en la que exista una orquesta juvenil. Los profesores que viajan junto con la YOA y sus miembros ensayan por secciones, junto a los jóvenes de la orquesta local, las obras programadas para la gira. Esta actividad es de gran alcance musical pero sobre todo social, solidario, de intercambio y desarrollo comunitario entre los y las jóvenes de las Américas, en una suerte de macroproyección de la labor iniciada en La Serena y que tal vez Jorge Peña soñó pero jamás pensó que podría suceder.

La gira en Chile se efectuó entre el 29 de junio y el 28 de julio del año en curso. Se inició con la residencia en La Serena -auspiciada por la Universidad de La Serena y la Intendencia de Coquimbo. Además de los ensayos parciales, se efectuaron talleres, tutorías, conferencias y conciertos. Luego prosiguió hacia el sur del país a las ciudades de Valparaíso, Santiago, Talca, Concepción y Frutillar. Fue dirigida por los maestros Benjamin Zander, Carlos Miguel Prieto, Hugo Domínguez y Felipe Hidalgo. Actuaron como solistas -entre otros- los excepcionales y virtuosos violinistas Timothy Chooi y Sarah Chang.

\section{HOMENAJE A JORGE PEÑA HEN}

Conversamos con el maestro Juan Orrego-Salas quien nos informó que el año 2011 recibió en su residencia en Bloomington un llamado telefónico de Mark Gillespie, Gerente General de la YOA, quien lo invitó a formar parte de la gira 2012 que la YOA cumpliría en Chile, 
para la que se había programado su Obertura festiva op. 21. Al informarse a sus 93 años del contenido humanista de la conmemoración que la orquesta haría de Jorge Peña en La Serena, el maestro decidió participar. El recuerdo oficial de la vida y obra de Jorge Peña fue presentado por el maestro Orrego-Salas, Premio Nacional de Arte en Música 1992, el pasado 8 de julio en La Serena.

El gerente Mark Gillespie de la YOA nos comunicó en La Serena un dato que deseábamos conocer: ¿de quién y dónde surgió la idea de honrar y conmemorar la labor de Jorge Peña como creador de la primera Orquesta Infantil de Latinoamérica? Mark Gillespie respondió: "fue del músico chileno Raúl Vergara Montoya, miembro durante tres años de la YOA, quien me visitó en nuestras oficinas de Washington DC en enero 2011. Al saber que la YOA había decidido venir a Chile al cumplir 10 años de existencia, sugirió que se dedicara la gira 2012 a la figura y trabajo de integración social y musical del compositor, director de orquesta y pedagogo maestro Jorge Peña Hen. La iniciativa fue aceptada y aprobada por la YOA".

El joven músico Raúl Vergara es serenense y fue alumno de percusión del maestro Raimundo Garrido Muñoz en la Escuela Experimental de Música "Jorge Peña Hen". Después de haber participado en la YOA, reside desde 2008 en Seúl donde es percusionista titular de la Orquesta Filarmónica coreana. Luego de conocer la aceptación de rendir un homenaje al maestro Peña Hen, R. Vergara encontró apoyo en el ingeniero Emil Le Roy y en el ex alumno de la Escuela Experimental Víctor Hugo Villagrán, quienes actuaron como coordinadores de la YOA en La Serena. De este modo se logró una masiva participación de la ciudadanía en los tres conciertos que se programaron los días 10, 11 y 12 de julio.

A este respecto conviene recordar que el nacimiento de las primeras orquestas infantiles y juveniles en Latinoamérica se produjo en la ciudad de La Serena-Chile- el año 1964 por iniciativa del maestro Jorge Peña Hen. Impulsado por los ideales de desarrollo musical y social de la infancia y en sintonía con los movimientos progresistas de la sociedad chilena de entonces, organizó los primeros conjuntos instrumentales de niños hasta fundar la Escuela Experimental de Música de La Serena con carácter estatal y gratuita. El proyecto fue rubricado por un decreto ministerial especial en 1965, el que permitió integrar la enseñanza y práctica colectiva de la música al plan curricular nacional desde el cuarto año básico hasta concluir el liceo. Este proyecto educativo se mantiene vigente en la asociación de esta escuela con el Departamento de Música de la Universidad de La Serena, de la cual soy académico titular ${ }^{1}$.

\section{JORGE PEÑA HEN (SANTIAGO 1928 / LA SERENA 1973)}

Jorge Peña Hen nació en Santiago pero su niñez transcurrió en Coquimbo. Luego de completar sus estudios musicales en piano, violín y composición en el Conservatorio Nacional de la entonces Facultad de Ciencias y Artes Musicales de la Universidad de Chile en Santiago, Jorge Peña regresó en 1950 a la ciudad de La Serena en la provincia de Coquimbo. Contrajo matrimonio un año después con la pianista Nella Camarda, con

\footnotetext{
${ }^{1}$ Ver a este respecto de Olivia Concha Molinari, "Orchestre infantili e giovani in Cile", Revista Musica/Realtà, XXXII/94 (marzo, 2011), Milán, Italia, pp. 5-9.
} 
la cual tuvo dos hijos, Fedora y Juan Cristián. Es en La Serena donde residió y se dedicó febril e incesantemente hasta el final de sus días a la organización de actividades musicales y culturales, y a impulsar nuevas propuestas de educación musical y del estudio profesional de la música.

Fue un líder entre los estudiantes universitarios, seguramente influenciado en parte por su padre, médico de profesión y militante socialista. En tal sentido Jorge Peña unió los ideales de progreso social al desarrollo de la sensibilidad y conocimiento musical. Incansable convocador, de carácter contagiosamente activo, Peña fundó la Sociedad Bach el mismo año 1950. Fue una institución apreciada por las autoridades musicales de la época quienes veían en el joven un ejemplo de pasión por la música, junto a una acendrada voluntad y capacidad de gestión cultural. Posteriormente sus ideas, propuestas, planes y programas de desarrollo musical fueron apoyados institucionalmente por la Universidad de Chile y el Ministerio de Educación.

Desde La Serena como centro cultural Jorge Peña desplegó su eficaz trabajo junto con su esposa y equipos de profesores y ciudadanos que confiaban en su liderazgo. Involucró a niños, jóvenes y adultos, en un accionar definido como apostolado por destacados músicos y la prensa chilena de la época. Conciertos, recitales, conferencias, clases, obras teatrales se sucedían incesantemente no sólo en La Serena, sino además en las ciudades cercanas. Con gran esfuerzo, tenacidad y compromiso se organizó y llevó a cabo en 1960 una magna presentación con solistas, coros y orquesta de la región de la Pasión según San Mateo de J.S. Bach.

En 1963 Jorge Peña viajó a Estados Unidos. En su reciente viaje a La Serena el maestro y compositor Juan Orrego-Salas manifestó lo siguiente: "Jorge fue mi alumno de composición durante un par de años; creo que el único Cuarteto de cuerdas que se conserva lo hizo durante ese período² ${ }^{2}$ Luego lo heredó como alumno Gustavo Becerra. Mi último encuentro con Jorge fue en Estados Unidos; el año 1963 él había recibido una invitación del Departamento de Estado para ir a visitar Escuelas de Música y una de ellas fue la de Indiana en Bloomington donde yo era profesor. Llegó Jorge Peña a nuestra casa y conversando con él -ahora lo recuerdo- noté que una de las iniciativas que más le interesaba investigar era el desarrollo de las orquestas infantiles en las diferentes ciudades de USA, auspiciadas muchas veces por las escuelas de música. Y ahí -creo yo- nació la inspiración de Jorge para establecer la orquesta de niños aquí en La Serena. Y esa fue la última vez que lo vi, hasta que supe la brutalidad que había sucedido con él en el año 1973”.

Jorge Peña observó la práctica colectiva musical en dichas escuelas por medio de orquestas y bandas y tomó nota de los métodos con los cuales se estudiaba, además del tipo de repertorio y la organización entre otros aspectos. Al regresar a Chile maduró la idea y se convenció que la práctica musical de niños y jóvenes en los colegios podría convertirse en un proyecto educativo de integración social como estrategia curricular de desarrollo de la infancia chilena, específicamente aquella más necesitada de oportunidades para

${ }^{2}$ Véase Catálogo de obras de Jorge Peña en Elizabeth Cortés, Jorge W. Peña Hen: vida y obra, Seminario de título para la obtención del título de Profesor de Estado en Educación Musical, La Serena: Facultad de Humanidades, Departamento de Música, Universidad de La Serena, 1994, p. 32. Profesor guía: Lina Barrientos. 
superar su injusta condición de pobreza. Peña emprendió con gran éxito la formación de orquestas y grupos musicales infantiles, no solamente en La Serena sino también en otras ciudades vecinas: Coquimbo, Ovalle, Copiapó y otras ubicadas más al norte. Para ello se seleccionaron niños en poblaciones y barrios populares por sus condiciones auditivas, rítmicas y de afinación.

Una evidencia de los logros de su proyecto es -como se mencionó anteriormente- la creación de la Escuela Experimental de Música de La Serena, aún vigente. Cuatro estudiantes de entonces se han transformado en profesores de música de esta Escuela -en violín, flauta, oboe y trompeta- mientras que un alto número de sus egresados integran en la actualidad diferentes orquestas profesionales chilenas.

Durante la década de los cincuenta no existía en la provincia el número de músicos profesionales requeridos para su proyecto musical. Debido a ello Peña buscó entre los profesores normalistas que tocaban violín y algunos aficionados a los primeros colaboradores para su Escuela Experimental. La experimentación consistía en la formación de grupos de niños pequeños (desde 9 años) que sin haber estudiado anteriormente música aprendían a leer partes de orquesta y/o banda en forma colectiva, además de asistir durante la semana a clases grupales de instrumento y de teoría y solfeo. Además del repertorio que había traído desde su viaje al extranjero, Peña se encargaba de transcribir y componer algunas piezas adecuadas y progresivas para los diferentes grupos etarios. Las orquestas infantiles y juveniles entre los años 1963 y 1973 crecieron cuantitativamente y progresaron en habilidades, hasta llegar a interpretar obras de nivel avanzado aun para orquestas profesionales.

Dos hitos señalan los progresos del proyecto: el primer concierto de la Orquesta Sinfónica Infantil en el Teatro Municipal de Santiago y el efectuado ante el Senado de la República el año 1965. Obtuvieron comentarios entusiastas y elogios de autoridades musicales en la Revista Musical Chilena y en la prensa santiaguina ${ }^{3}$. El estreno de la ópera La Cenicienta con música de Jorge Peña para solistas, coro y orquesta fue interpretada por niños y jóvenes en La Serena durante el siguiente año 1966.

\section{$1972-1973$}

Un cierto número de músicos de diferentes universidades e instituciones musicales de Chile fuimos invitados a La Serena por Jorge Peña en 1972 con el fin de escuchar a las orquestas de la Escuela Experimental y a otras orquestas de las ciudades cercanas (Ovalle, Copiapó). Durante dos jornadas de audiciones y diálogos sobre el trabajo desarrollado, tuvimos en aquella ocasión la posibilidad de admirar y felicitar a los niños, a los profesores y a Jorge Peña, pero también pudimos discutir con él sobre la marcha y las proyecciones que veíamos del proyecto, con preocupaciones legítimas por parte de algunos de nosotros. Peña flexiblemente aceptó críticas pero también expuso con mucha fuerza sus convicciones: su ideal de hacer música con y para los niños iba más allá de los resultados estéticos y técnicos.

${ }^{3} \mathrm{Al}$ respecto ver de Luis Merino, "In memoriam Jorge Peña Hen 1928-1973", RMCh, XXVII/123124 (julio-diciembre, 1973), pp. 87-88. 
La suya era una misión de gran vuelo social y cultural que se había autoimpuesto y que lograba llevar adelante con gran ímpetu al persuadir y convencer no solamente a los niños que lo amaban mucho, sino también a sus familias y a quienes, como algunos de nosotros, teníamos algo que objetar.

Su trascendental trabajo traspasó las fronteras geográficas en diferentes giras efectuadas con la Orquesta Sinfónica Infantil a Argentina, Perú y Cuba.

El 11 de septiembre de 1973 estalló el golpe de Estado en Chile. Jorge Peña Hen fue detenido en La Serena junto con otros ciudadanos. Ulteriormente fue torturado y fusilado el 14 de octubre por la "caravana de la muerte". Estaba integrada por fuerzas militares especiales que partieron desde Santiago con la orden específica de eliminar a determinadas personas, sin ningún tipo de proceso ni posibilidades de defensa en diferentes ciudades del país.

\section{DIFUSIÓN}

La idea, el trabajo y la convincente estrategia de Jorge Peña para involucrar desde la infancia la práctica y el estudio musical en conjuntos instrumentales tuvieron la posibilidad de extenderse en 1974 hasta Venezuela gracias a tres profesores de La Serena, exiliados en ese país, quienes habían sido colaboradores en Chile de Peña Hen: Hernán Jerez, Pedro Vargas y Sergio Miranda . En la ciudad de Carora ellos comenzaron a replicar las experiencias vividas en Chile en este trabajo musical-social, el que fue conocido por autoridades venezolanas de la época, las que aplicaron y desarrollaron con gran eficacia esta idea.

El maestro José Antonio Abreu, Ministro de Cultura de Venezuela en ese período, fue el fundador del sistema de orquestas en su país. Con ocasión de una gira de la Sinfónica Nacional Juvenil venezolana en Santiago el año 1996, se refirió a lo significativo de la obra de Jorge Peña, "reconociendo en ella la semilla y punto de partida para el movimiento que se desarrolló en Venezuela y diversos otros países hermanos"5.

Con el regreso de la democracia en Chile se organizó en 1999, gracias al compromiso del maestro Fernando Rosas y del gobierno del presidente Ricardo Lagos, una red de orquestas infantiles y juveniles a nivel nacional en base al proyecto serenense que se mantiene vigente hasta hoy. Esto ha permitido la constitución de al menos 300 orquestas en 170 municipalidades de Chile, que involucran aproximadamente a 15.000 niños y jóvenes a los cuales se otorga una beca para la adquisición de instrumentos, partituras, cuerdas ${ }^{6}$. El espíritu constructivo, la música como pasión, el compromiso social de Jorge Peña Hen resiste y le sobrevive.

${ }^{4}$ Agradezco al colega Hugo Domínguez, Director de la Orquesta Juvenil "Jorge Peña Hen" de La Serena por su aporte.

${ }^{5}$ Miguel Castillo Didier, Jorge Peña Hen: músico, maestro y humanista mártir (Santiago: Miguel Castillo Didier, 2001), p. 259.

${ }^{6}$ www.orquestasjuveniles.cl. 
Es por ello que la noble idea y gestión de Raúl Vergara tuvo una importante resonancia. Nos parece que la gira de conciertos de la YOA 2012 en Chile es el más justo reconocimiento póstumo que Jorge Peña Hen merecía de la comunidad tanto nacional como internacional. 